\title{
PENGADAAN AIR BERSIH DENGAN PEMANFAATAN TEKNOLOGI TENAGA GRAVITASI DI DUSUN PELAN KEREP DESA SUMBERKARE KECAMATAN WONOMERTO KABUPATEN PROBOLINGGO
}

\author{
Yustina Suhandini Tjahjaningsih ${ }^{1)}$, Sri Andayani ${ }^{2)}$, Aries Budi Wijayanto ${ }^{3)}$ \\ yustinasuhandini@upm.ac.id ${ }^{1)}$, sriandayani@upm.ac.id ${ }^{2)}$, \\ arisbudiwijayanto@gmail.com ${ }^{3)}$ \\ Teknik Industri, Fakultas Teknik, Universitas Panca Marga Probolinggo 1), \\ Sastra Inggris, Fakultas Sastra dan Filsafat, Universitas Panca Marga ${ }^{2)}$, \\ Teknik Industri, Fakultas Teknik, Universitas Panca Marga ${ }^{3)}$
}

\begin{abstract}
ABSTRAK
Dusun Pelan Kerep Desa Sumberkare Kecamatan Wonomerto Kabupaten Probolinggo memiliki struktur tanah berbatu sehingga sulit mendapatkan sumber air tanah. Sehari-hari, masyarakat memanfaatkan air sungai atau membuat galian tanah di sekitar sungai sebagai wadah resapan air sungai. Kondisi air tidak layak digunakan untuk memenuhi kebutuhan sehari-hari. Airnya hijau, kotor, dan cenderung berbau karena sungai ini menjadi sungai aliran buangan limbah dan kotoran dari desa-desa sebelumnya. Pelayanan air bersih dari BPBD tidak menjangkau dusun ini karena letaknya yang cukup jauh dan lokasinya yang menanjak. Kondisi ini membuat rendahnya kualitas kesehatan warga. Solusi permasalahan tersebut adalah pengadaan lima tandon dan pipanisasi dengan menggunakan teknologi tenaga gravitasi, yang mengalirkan air bersih dari BPBD ke pemukiman warga sejauh 827 meter. Teknologi ini memiliki berbagai kelebihan baik secara aspek ekonomi, budaya, dan kesehatan. Dengan terpenuhinya kebutuhan sekitar $65 \mathrm{KK}$ atau \pm 390 Jiwa akan air bersih, diharapkan menjadikan kualitas hidup masyarakat juga semakin meningkat.
\end{abstract}

Kata Kunci: Dusun Pelan Kerep, Pengadaan Air, Teknologi Tenaga Gravitasi

\section{PENDAHULUAN}

Desa Sumber Kare adalah sebuah desa yang terletak di Kecamatan Wonomerto, Kabupaten Probolinggo, Propinsi Jawa Timur. Secara geografis, Desa Sumber Kare ini berada di bagian Barat Kabupaten Probolinggo, yang mempunyai batas wilayah sebelah Utara adalah Kecamatan Sumberasih, sebelah Timur dengan Kecamatan Bantaran dan Kota Probolinggo, sebelah Selatan 
dengan Kecamatan Kuripan, dan sebelah Barat dengan Kecamatan Tongas dan Lumbang.

Berada pada ketinggian 120 meter dpl, kawasan desa ini beriklim tropis. Temperatur udaranya relatif panas, yaitu antara $36{ }^{0} \mathrm{C}-39{ }^{0} \mathrm{C}$. Desa Sumber kare terdiri dari empat dusun, yaitu Dusun Pelan Kerep, Dusun Krajan, Dusun Karang Kare, dan Dusun Gedangan. Keempat Dusun tersebut terbagi menjadi 4 RW dan $18 \mathrm{RT}$.

Tiga dari empat Dusun di Desa Sumber Kare cenderung tidak memiliki masalah dengan pemenuhan air bersih. Namun, Dusun Pelan Kerep berbeda dengan tiga dusun yang lain. Dusun ini sangat kekurangan air bersih. Masyarakat memenuhi kebutuhan air bersih dengan memanfaatkan air sungai yang mengaliri dusun tersebut atau membuat galian-galian di tanah sekitar sungai sebagai wadah resapan dari air sungai. Kualitas air sungai maupun resapannya sangat buruk. Warna airnya hijau dan sedikit berbau sehingga tidak layak digunakan untuk kebutuhan minum, mandi, sikat gigi, cuci baju, cuci piring, bahkan menanak nasi. Hal ini terpaksa dilakukan karena tidak adanya sumber air lain yang dapat dimanfaatkan dengan mudah.

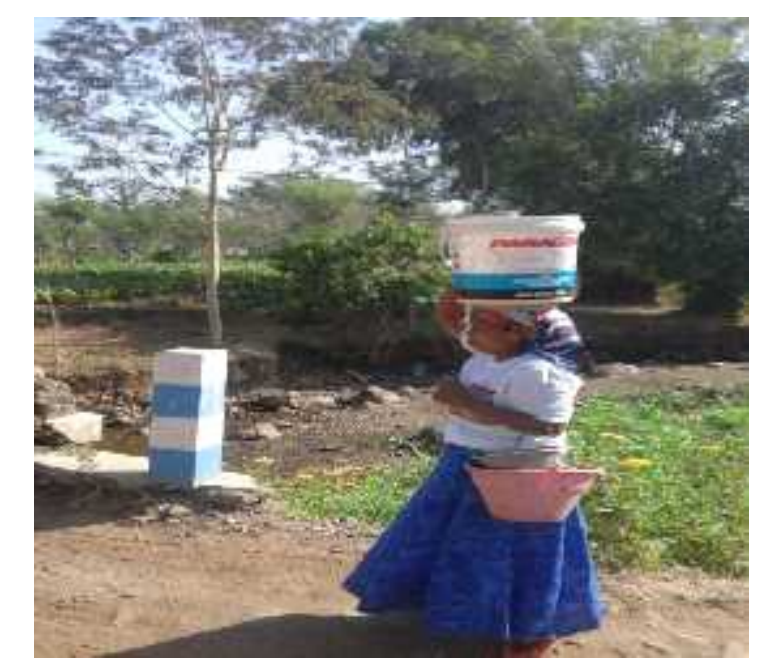

Gambar 1. Pengambilan air dari genangan air sungai 


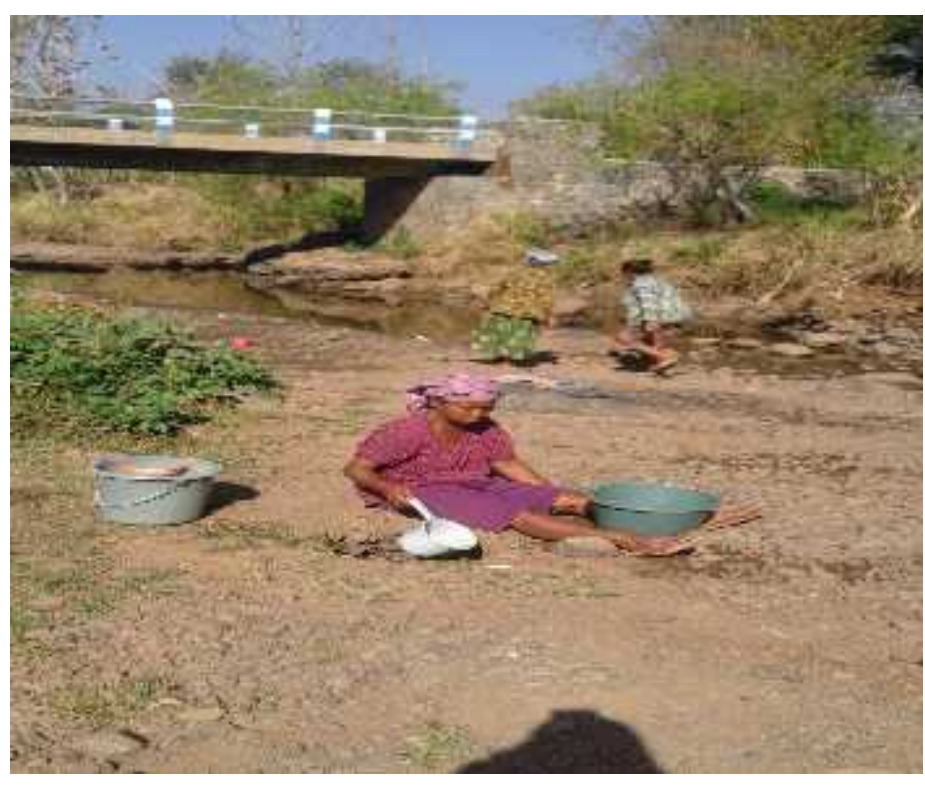

Gambar 2. Pengambilan air dari resapan genangan sungai

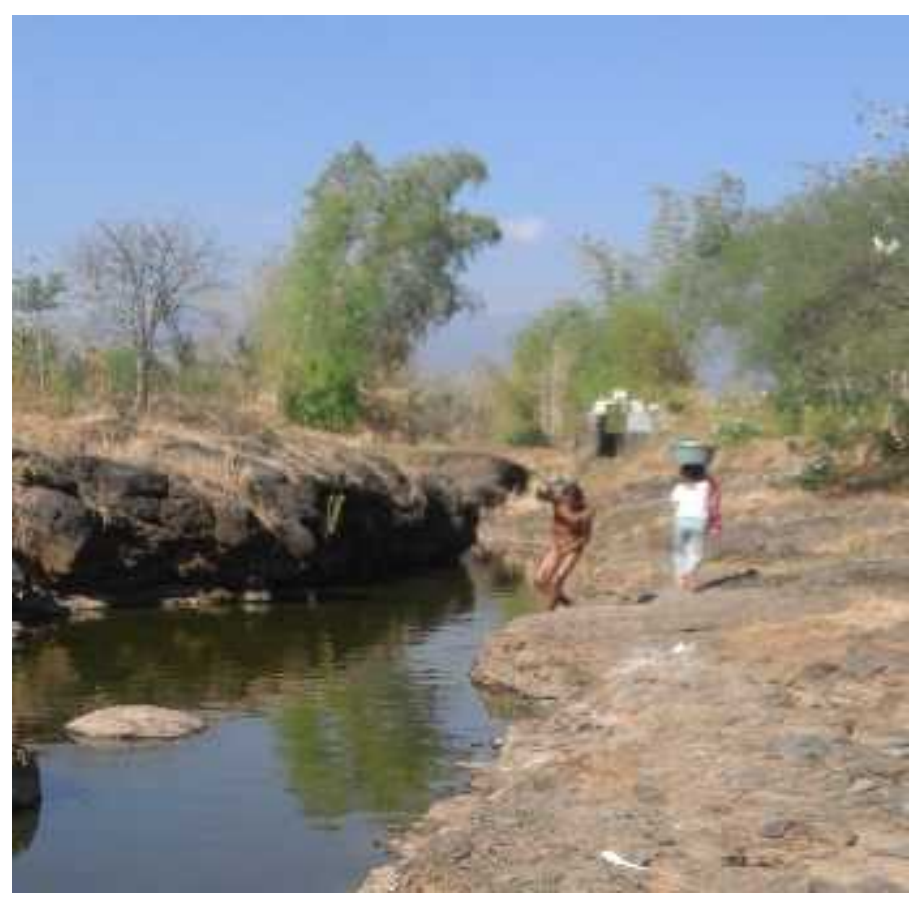

Gambar 3. Warga Dusun Pelan Kerep RT 4 RW 5 Mandi di Genangan Air Sungai yang Berwarna Hijau

Di Desa Sumberkare sebenarnya, terdapat bak penampung air bersih yang disediakan oleh BPBD. Namun, lokasi yang agak jauh menyebabkan aliran air bersih ini tidak dapat dengan mudah dinikmati warga Dusun Pelan Kerep. Jika 
ingin mendapatkan air tersebut, mereka harus menggunakan sarana transportasi seperti sepeda motor atau sepeda kumbang agar tidak berat karena kondisi jalannya setapak dan makadam. Sayangnya kendaraan sepeda motor atau sepeda kumbang jarang dimiliki oleh warga karena kondisi kemiskinan. Dengan kondisi seperti ini, masyarakat terpaksa menggunakan air sungai dan resapannya yang sebenarnya tidak layak pakai. Keadaan ini membuat tingkat kesehatan warga dusun ini juga cenderung rendah. Penyakit kulit yang diderita warga menjadi pemandangan yang sudah biasa ditemui sehari-hari.

Permasalahan utama yang harus dicarikan solusinya pada program pengabdian masyarakat ini adalah kesulitan mendapatkan air bersih bagi warga Dusun Pelan Kerep Desa Sumber Kare. Jadi tujuan program ini adalah pengadaan air bersih bagi warga Dusun Pelankerep Desa Sumber Kare. Pengadaan air bersih ini dapat dimanfaatkan oleh dinikmati oleh sekitar $65 \mathrm{KK}$ atau \pm 390 Jiwa. Ketersediaan air bersih ini pastinya sangat berpengaruh pada kenaikan tingkat kualitas kesehatan warga.

Pada beberapa studi kasus sebelumnya, untuk mengatasi daerah yang kekurangan air adalah dengan menggunakan beberapa metode pengadaan air. Metode tersebut antara lain dengan pengadaan perpipaan dengan sistem pengaliran pompa (Tuames, 2015), dan penggunaan sistem gravitasi (Kaunang, 2015; Makawimbang, 2017).

\section{METODE}

Permasalahan akan ketersediaan air bersih di Dusun Pelan Kerep Desa Sumberkare diselesaikan dengan metode pengadaan air bersih dengan memanfaatkan teknologi tenaga gravitasi. Metode ini dilaksanakan dengan cara mengalirkan air bersih dari bak penampungan air BPBD dengan sarana pipanisasi menuju tandon-tandon yang tersebar di 5 titik wilayah Dusun Pelankerep. Pemanfaatan tenaga gravitasi dipilih menjadi metode penyelesaian permasalahan pada program pengabdian masyarakat ini, karena metode ini relatif ekonomis dan praktis. Teknologi tenaga grafitasi ini tidak memerlukan bahan bakar maupun tenaga listrik. Sistem teknologinya juga cenderung sederhana jadi tidak 
memerlukan keahlian khusus bagi warga yang notabene berpendidikan rendah untuk menjaga keberlangsungan pengadaan air bersih ini. Beda Ketinggian antara wilayah Dusun Pelankerep dengan bak penampungan air BPBD juga cenderung tidak terlalu jauh, sehingga pemanfaatan tenaga grafitasi masih memungkinkan untuk dilakukan.

Metode pemanfaatan teknologi tenaga gravitasi ini dilakukan dengan 1) merancang/mendesain peta jaringan pipa sekaligus meletakkan Gate Valve dan Air Valve pada lokasi yang tepat; 2) merancang/mendesain lokasi 5 tandon air sekaligus pembuatan bangunan dari batu kali melingkar dengan diameter 1,5 M tinggi $0,5 \mathrm{~cm}$ dan batu bata berukuran $2 \times 1,5 \times 1$ (dalam meter) yang digunakan sebagai pondasi dan dudukan tandon air; 3) menguji coba aliran air agar supaya pengalirannya merata sekaligus mencuci pipa agar senua kotoran yang ada pada pipa bisa keluar semua sehingga kondisi pipa bersih dan higienis; 4) mengalirkan air dengan pipanisasi yang telah dirancang menuju tandon-tandon agar dapat dimanfaatkan oleh warga sekitarnya.

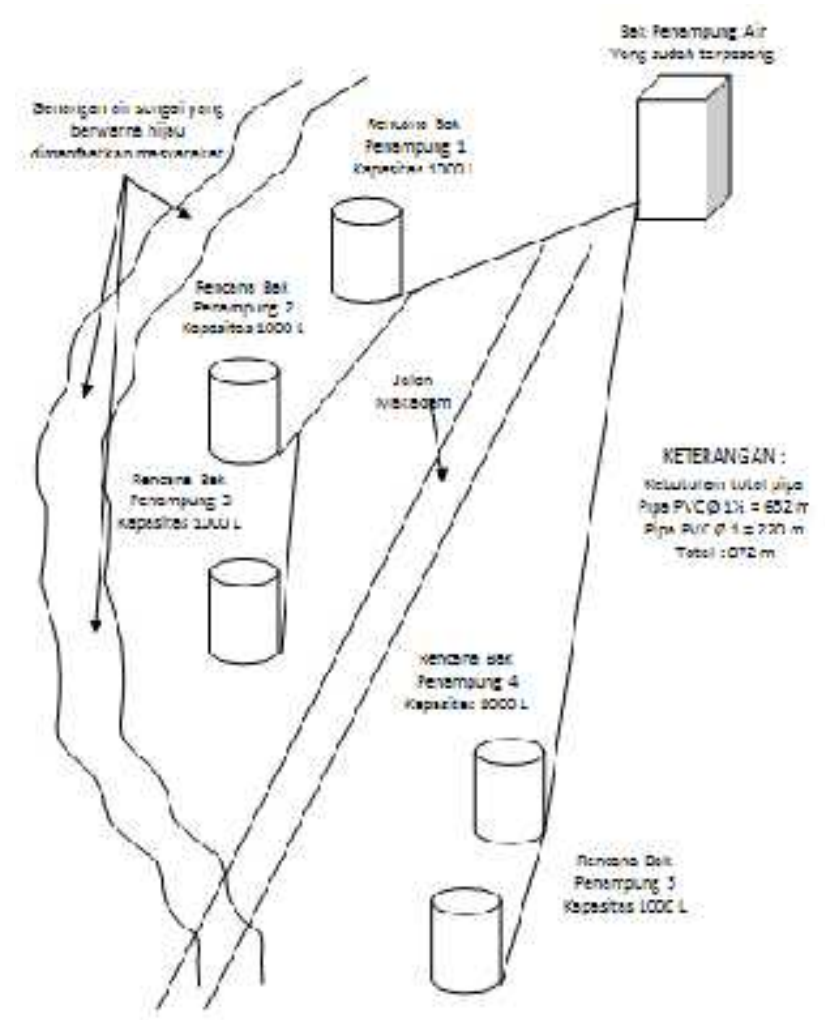

Gambar 4. Peta Jaringan Pipanisasi pada 5 Tandon Air 


\section{HASIL DAN PEMBAHASAN}

Pengadaan air bersih di Dusun Pelankerep Desa Sumber Kare diwujudkan dengan memanfaatkan teknologi tenaga gravitasi. Teknologi ini memanfaatkan beda ketinggian air dari bak penampungan BPBD ke lima titik lokasi tandon. Air yang tertampung dialirkan melalui pipanisasi yang dialirkan secara bertahap dari satu tandon menuju tandon yang lain. Secara terperinci pengadaan air dengan pemanfaatan teknologi tenaga grafitasi dilakukan dengan pengadaan pipanisasi yang dialirkan secara gravitasi dari bak penampung yang ada kemudian ditampung dengan 5 tandon air secara terpisah dengan jaraknya $872 \mathrm{~m}$. Lokasi kelima tandon yang tersebar di Dusun Pelankerep berada pada daerah yang lebih rendah dibandingkan lokasi bak penampungan BPBD. Sementara pipanisasi yang dilakukan terdiri dari sebagai berikut.

a) Bak Penampung BPBD

Bak penampung air merupakan sumber air yang akan dialirkan menuju 5 titik tandok di Dusun Pelan Kerep. Bak ini merupakan fasilitas desa yang sebelumnya telah mengaliri tiga dusun lainnya di Desa Sumberkare

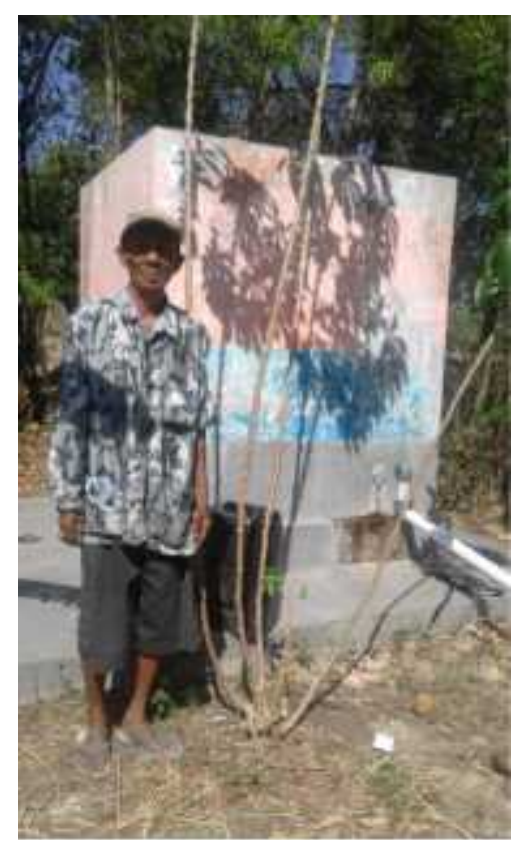

Gambar 5. Bak Penampungan Air BPBD 
b) Gate Valve

Gate Valve diperlukan sebagai alat pengatur air untuk mengkondisikan agar air bisa dengan merata dialirkan ke lima titik tandon. Pemerataan pengaliran air dilakukan agar aliran air dapat dinikmati oleh sebagian besar masyarakat Dusun Pelankerep yang sangat membutuhkan aliran air bersih. Spesifikasi Gate Valve adalah dengan diameter $(\varnothing)$ 1/1/2 dan Air Valve $\varnothing$ 1/1/2".

c) Air Valve

Air Valve adalah alat pembuang udara pada pipa distribusi yang diletakkan pada daerah gundukan yang biasanya tersimpan udara yang bisa menghambat lajunya air bersih. Spesifikasi Air Valve adalah dengan diameter (Ø) 11/2".

d) Pipa Distribusi

Pipanisasi ini mengalirkan air dari bak penampungan air BPBD menuju lima tandon yang menyebar sejauh 827 meter. Spesifikasi: Pipa PVC diameter 1 1/2“" sebanyak 163 lonjor @ 4 meter (652 meter). Pipa PVC dia 1" sebanyak 55 lonjor @ 4 meter (220 meter)

e) Tandon penampungan air (Water Collector)

Tandon ini menjadi penampungan air dari aliran air yang berasal dari bak penampungan air BPBD. Tandon ini tersebar di lima lokasi di Dusun Pelan Kerep. Masing-masing tandon diletakkan di atas pondasi batu bata dan dinikmati oleh kurang lebih 10-15 keluarga. Spesifikasi tandon air adalah dengan kapasitas 1100 liter sebanyak 5 buah.

f) Pondasi Tandon

Pondasi tandon air adalah tempat dudukan tandon air yang dipasang di 5 titik lokasi. Spesifikasi pondasi adalah memiliki diameter $1,5 \mathrm{M}$ tinggi $0,5 \mathrm{~cm}$ dan Batu bata berukuran 2 x 1,5 x 1 (dalam meter). 


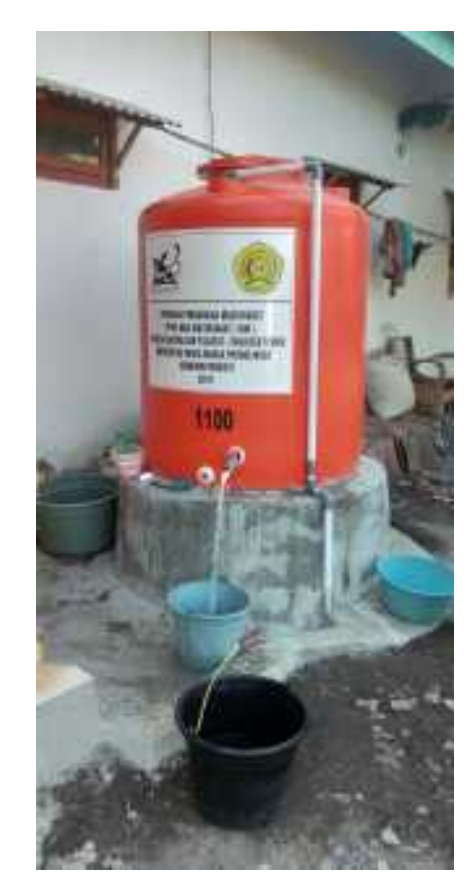

Gambar 6. Tandon Air yang Dipasang di Lokasi

\section{KESIMPULAN DAN SARAN}

\section{KESIMPULAN}

Kebutuhan air bersih yang menjadi permasalahan penduduk Dusun Pelan Kerep Dusun Sumber Kare Kecamatan Wonomerto Kabupaten Probolinggo Provinsi Jawa Timur diatasi dengan teknologi tenaga gravitasi. Teknologi tenaga gravitasi ini diwujudkan dalam pengadaan tandon dan pipanisasi yang dipasang pada lima lokasi. Pipanisasi berfungsi untuk mengalirkan air dari bak penampungan air BPBD menuju lima lokasi yang letaknya lebih rendah, secara bertahap dari tandon 1 ke tandon 2, 3, 4, dan 5 sejauh 827 meter. Program pengabdian masyarakat Hibah Kemenristekdikti ini (PKM) dapat dinikmati oleh sekitar $65 \mathrm{KK}$ atau \pm 390 jiwa.

Teknologi tenaga gravitasi ini memiliki berbagai kelebihan baik secara aspek ekonomi, budaya, dan kesehatan. Secara ekonomi, sistem ini tidak memerlukan bahan bakar maupun tenaga listrik, sehingga tidak memerlukan biaya operasional yang membebani masyarakat. Mereka juga dapat menghemat tenaga dengan tidak mengangsu air dengan timba atau jerigen ke rumah masingmasing. Dari aspek budaya, hal ini diharapkan dapat mengubah kebiasaan 
penduduk untuk tidak lagi menggunakan air sungai yang kotor. Dengan terpenuhinya kebutuhan warga akan air bersih, diharapkan menjadikan tingkat kesehatan masyarakat lebih terjaga.

\section{SARAN}

Pengadaan air bersih dengan menggunakan teknologi tenaga gravitasi ini merupakan salah satu solusi permasalahan bagi warga di Dusun Pelan Kerep Desa Sumberkare Kecamatan Wonomerto Kabupaten Probolinggo. Pengadaan air bersih ini hanya mengatasi ketersediaan air bersih untuk keperluan warga seharihari. Namun kemiskinan yang mewarnai kehidupan warga dan keterbatasan program penelitian ini belum menjangkau pengadaan MCK bagi warga dan pengadaan air untuk daerah pertanian yang menjadi salah satu sumber penghasilan warga. Diharapkan program-program pengabdian masyarakat selanjutnya dapat menjangkau keterbatasan ini dengan melanjutkan penanganan permasalahan lainnya di lokasi ini.

\section{DAFTAR PUSTAKA}

Tuames, dkk, 2015. Perencanaan Teknik Jaringan Perpipaan Air Bersih dengan sistem Pengaliran Pompa di Desa Susulaku Kecamatan Insana, Kabupaten Timor Tengah Utara, Jurnal Teknik Sipil Vo. IV, No. 1.

Kaunang, C.D., dkk. 2015. Mengembangkan Sistem Penyediaan Air Bersih di Desa Maliambo Kecamatan Likupang Barat Kabupaten Minahasa Utara. Jurnal Sipil Statik, Vol.3 No. 6 (361-372), ISSN 2337-6732.

Makawimbang, F.A, dkk. 2017 Perencanaan Sistem Penyediaan Air Bersih di Desa Soyowan Kecamatan Ratatotok Kabupaten Minahasa Tenggara. Jurnal Teknik Sipil, Vol. 5 No. 1 Hal. 31-40, ISSN 2337-6732. 